\title{
Support for Different Roles in Software Engineering Master's Thesis Projects
}

\author{
Martin Höst, Member, IEEE, Robert Feldt, Member, IEEE, Frank Lüders, Member, IEEE
}

\begin{abstract}
Like many engineering programs in Europe, the final part of most Swedish software engineering programs is a longer project in which the students write a Master's thesis. These projects are often conducted in cooperation between a university and industry, and the students often have two supervisors, one at the university and one in industry. In particular, the Bologna Process that is currently underway to align different higher educational programs in Europe, discusses industrial Master's theses as a major type of thesis project. However, there is a lack of knowledge on how best to support these projects and the different stakeholders involved. This paper presents a study where students and supervisors from software engineering Master's thesis projects at three different Swedish universities are interviewed. The intention of the study is to explore what the major problems of different stakeholders are during a project, and to investigate what type of support is needed. Based on the interview results, a support model is defined, which outlines the different types of support that are needed for different roles in Master's thesis projects.
\end{abstract}

Index Terms-Communication systems, computer science education, engineering education, software engineering, software testing

\section{INTRODUCTION}

$\mathbf{M}$ ANY engineering education study programs are ended with a longer project that is carried out by one or two students. The intention is that the students should use knowledge they have gained during their studies, and synthesize knowledge from earlier courses. They should also show that they are able to carry out this kind of work independently, without detailed support from a teacher or other person.

This kind of project is referred to in different ways in different countries and universities, often as "thesis projects" or "dissertation projects." The projects can be conducted at different educational levels, from the Bachelor's level to Doctoral level. The focus of this paper is on the Master's level, which is the level between the Bachelor's and Doctoral levels. Throughout this paper the projects will be referred to as "Master's thesis projects," or simply "thesis projects."

Through international discussions and working groups, there are now guidelines available, which describe the important parts of software engineering educational programs. For example, in [1] guidelines for undergraduate programs are presented, and there is now some consensus on which subjects and courses are crucial in software engineering education. However, fewer detailed guidelines are available concerning how

This work was supported by the Swedish Agency for Networks and Cooperation in Higher Education (NSHU).

M. Höst is with Department of Computer Science, Lund University, Sweden, e-mail: martin.host@cs.lth.se.

R. Feldt is with Blekinge Institute of Technology, Sweden

F. Lüders is with Mälardalen University, Sweden
Master's thesis projects should be conducted and supported by universities. Even in the Graduate Software Engineering Reference Curriculum (GSwERC), currently under development, no concrete support for so-called "capstone experiences" is given [2]. Since no guidelines are available to support the research-oriented nature of thesis projects at Master's level, there is thus a need for information on how to conduct and support Master's thesis projects.

For many students the thesis project is very different from their earlier studies. In earlier courses they have been more supported by teachers, and the contents of the courses have to a large extent been predefined. They may have been involved in student projects, where they have cooperated with other students with their objective being to deliver a product after the project, but they have, in many cases, not worked independently as they would in a thesis project. In the thesis project they are expected to take a larger part in formulating objectives and planning, and they are expected to conduct the project in an independent way, without detailed support and management from others. However, they are, of course, not conducting the project without any support at all. There are a number of different roles involved in this kind of project. There is a supervisor whose objective is to support the student in his/her work on assignments, and there is an examiner responsible for approving the work.

In many countries the thesis project is commonly conducted in cooperation with industry, or another organization external to the university, such as a governmental organization. Wohlin and Regnell [3] identify this structure as one way of achieving industrial relevance in engineering education. In this type of project the student typically gets access to an office space at the company and works on questions that are both of interest to the external organization, and of sufficient technical and methodological depth to be accepted as a thesis project at the university. If the thesis project is conducted in cooperation with industry, the student has, in addition to the roles mentioned above, a supervisor in industry, generally a person employed by the company.

There is not much support available for the different roles in this kind of project, and not much research has been conducted on how these projects are carried out. This type of support could be useful for those undertaking these different roles. This study reports on semi-structured interviews with individuals in different roles in industrial thesis projects. The focus is on the kind of support that is needed to ensure the completion of a successful thesis project.

The outline of this paper is as follows. In Section II background material on thesis projects and related research is presented. In Section III the research methodology is pre- 
sented, and in Section IV the empirical results of the conducted interviews are presented. The interview results are further discussed in Section V, and in Section VI conclusions and recommendations are summarized.

\section{BACKGROUND AND RELATED WORK}

To some extent, thesis projects have similarities with large project courses where software is developed. In this type of course, the students cooperate with a common objective to deliver a software product. The teachers of the course invest effort in making the project as realistic as possible and thus making it similar to actual industrial projects, through the choice of realistic assignments, working processes, and tools. The design of and experience with, this kind of course are, for example, presented in [4] and [3]. Thesis projects that are conducted in cooperation with industry are also realistic in terms of assignments and processes, since industry members are involved in planning the work. Differences between a thesis project and a project course in software engineering include the thesis project being conducted by fewer persons, the objective in many cases involving something other than software development, and the project actually being conducted in industry, as opposed to an environment that is intended to be similar to industry. That there are different ways to complete a Master's level education in software engineering is also confirmed by the recent GSwERC proposal [2] that differentiates between three types of such 'capstone experiences': a project, a practicum, or a thesis. While a project can be a practically-oriented undertaking, either by a single student or a group of students, a practicum is always done by a group of students and with a real, external customer. In contrast, a thesis is always done individually, focuses on software engineering research and has the support of a faculty member [2]. The theses referred to in this paper can be considered to be a mix of a practicum and a thesis in the parlance of [2]. This type of thesis can be done individually or in pairs of students and should involve application of knowledge from their previous education. A majority of the theses have a real, external customer but there are exceptions. The degree of research and original contribution can vary between different universities.

Wohlin and Regnell [3] present industrial Master's thesis projects as one of several ways to achieve industrial relevance in engineering education. Other means include project courses, having $\mathrm{Ph} . \mathrm{D}$. students and those with industry experience as teachers, and guest lecturers from industry.

Andersson et al investigated the interpersonal dynamics between supervisors and students in Master's thesis projects in a faculty of education [5]. They focused on the different views held of the purpose of the projects. The results show the duality inherent in any supervision situation: the supervisor should both support the student, and shape and direct the quality of the work.

While the research on Master's thesis projects is limited, more studies have been published that examine the undergraduate and doctoral levels. Hammick and Acker [6] focus, for example, on how differences in gender among supervisors affect how they approach their supervision of undergraduate theses, while Todd et al [7] describe the perceptions and experiences of social science undergraduates during their thesis work. In the latter study, the support from supervisors that was most appreciated was constructive feedback on draft work, as well as advice on relevant sources of information and the encouragement of creative thinking. Students also pointed out the importance of getting help in defining research questions and selecting the right methodology, and being given a structure with clear deadlines to structure the work. Students got little support from peers since their topics were often quite different. It is not clear if these experiences are also valid at the Master's level or for engineering students. The differences between Master's and the lower and higher levels is probably quite significant. For example, compared to a Ph.D. the time available is considerably less, there are less requirements that the result be publishable, and in general, there is more focus on industrial applicability. Compared to the undergraduate level, the Master's thesis should make a real contribution to knowledge, in that it needs to be more unique compared to the state-of-the-art.

Even outside of the engineering area there is a dearth of studies on Master's theses and how to support them. Ylijoki [8] interviewed 72 students in Finland about their views on their Master's degree studies. The focus was on the thesis writing and its problems. The results showed that students have four main different views on their studies, and that these views need to be taken into account in order to improve the supervision of thesis writing.

The basic problem students have in writing their thesis and conducting their projects is the transition they have to make from being consumers to producers of knowledge. Often for the first time in their studies the thesis project requires them to work independently, discover essentials and engage in critical thinking [9]. It is also relevant that students have different study orientations towards their thesis writing: academicallyoriented students aim to develop critical thinking, careeroriented students aim to improve their professional qualifications, and goal-oriented students aim to get the degree done [8].

An important factor in any project focusing on higher education in Europe is the Bologna Process (BP), an ongoing initiative to align educational programs in the European countries by 2010 [10]. The countries within the European union have had very different educational structures. This has made it hard to compare university degrees and has been an impediment to increasing exchange and mobility for students and work force between them. The Bologna Process aims to unify the many divergent academic awards, curricula and course structures, and examination practices within the European higher education system [10].

The continued work within the Bologna Process has identified action lines where the 46 participating European countries will work on aligning their higher educational systems to create a 'European Higher Educational Area' (EHEA). Even though it is not clear how this will directly affect Master's theses, an area in which there is considerable variation between individual countries [11], the following action lines are relevant for Master's theses and thus for this study: that there 
should be (a) easily readable and comparable degrees, (b) twocycle degrees (undergraduate and graduate), (c) a common system of credits (ECTS), (d) promotion of quality assurance, and (e) third-cycle degrees (doctoral studies). This means that within the EHEA there will be a clear three-level structure with Bachelor's, Master's and Doctoral degrees, that each degree will finish with a thesis project, that the learning outcomes of these thesis projects will have to be specified. It is also likely that theses will be judged and graded using the same ECTS grading system that other courses within the EHEA will use. The Bologna documents have noted the difference between research and industrial theses, as well as the existence of hybrids combining these two types, but concrete definitions or support are as yet unavailable [12].

The Bologna Process does not specify how to achieve the goals outlined in its declarations. However, since 2000 the European Commission has funded the Tuning project, which has been working to make the goals a reality [13]. The Tuning framework specifies levels of learning to be achieved at the different educational cycles (Bachelor's, Master's, Doctoral). The reference points can be either generic or subject-specific. Even though subject-specific competences are the basis for university degree programs, Tuning has highlighted the importance of also developing generic skills that prepare students for their future role in society and increases their employability. Tuning also states the overall goal for the Master's level degree that "the student ... must be able to execute independent (applied) research" and lists as one of the individual learning outcomes that the student should "be able to make an original, albeit limited, contribution within the canons of the discipline, e.g., final thesis" [13].

Concrete recommendations for how the Bologna Process affects Master's programs is not available, but especially at the Helsinki meeting in 2003 some consensus was reached as to their length, functions and profiles. However, in practice Reichert et al found that there is still considerable variation between universities [14].

Few studies have been published on the actual effect the Bologna Process has had on engineering curricula and their Master's thesis projects so far. In [15] it is described how the Computer Science and Engineering Master's program at ETH in Zurich has been adapted to the Bologna Process. The objective of the ETH Master's curriculum at ETH is to prepare students for a successful career in research in industry and/or in academia. Thus the four-month project that concludes the curriculum should teach the students to work independently on a scientific project. However, despite the overall objective of the curricula, it is not clear if these projects can be done in cooperation with industry or how the different stakeholders in such projects are to be supported in their roles.

In summary, there has not been much focus on thesis projects, either in respect to research or in support for teaching. There is now an ongoing European initiative where these questions are considered as important, even if there have not as yet been many specific results about thesis projects.

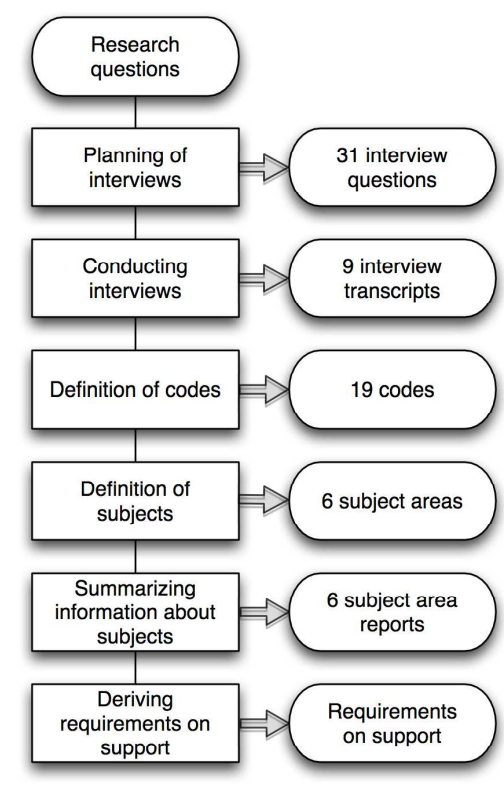

Fig. 1. Outline of the research methodology

\section{Methodology}

\section{A. Introduction}

The following research questions have been investigated:

1) What objectives do different stakeholders have with theses when they are being formulated?

2) What are the expectations for the quality of the thesis contents by the different stakeholders?

3) What are the main challenges for the different stakeholders during a thesis project?

4) What support is needed by those in the different roles during planning and execution of theses?

The research has been conducted with qualitative methods, where the analysis of interview data allows conclusions to be drawn. The objective was to focus more on the depth of the interviews, than it was to obtain a large set of data points and thereby be able to draw statistically-significant conclusions. Instead the objective was to rely on what Yin [16] describes as "analytic generalization." This means that the applicability of the findings in different situations must be based on a knowledge of the area, and the understanding that derived models and conclusions are valid.

The steps followed in conducting the research are presented in Fig. 1 and below.

\section{B. Steps of the Research}

1) Planning of interviews: Based on the research questions, interviews were planned and a number of interview questions were derived. This process resulted in 31 interview questions. Some concerned a general characterization of the subject and the thesis, but other questions were grouped according to which phase of a thesis project they are mostly related to (start-up, planning, execution, conclusion). The intention was not that all questions should be asked in the order as in which 
they were written, but rather that they could be used to check that all relevant areas were covered. According to Robson [17] this format is that of a semi-structured interview with open but specific questions. Due to page limitations all questions are not listed here, but examples are:

- Where did the thesis idea come from?

- Why was this topic seen as suitable for a thesis project?

- What methodology was chosen?

- What support did the students get from the organization?

- How was the work reported to the organization?

The questions were rather open. The intention was to allow for reflection and letting the interviewees describe how they worked in this area, which according to [18] is better than detailed questions and series of questions in a semi-structured interview.

2) Conducting interviews: In this step, nine interviewees were identified and contacted. Since the objective was not to obtain statistically significant differences but to obtain as much understanding of the area as possible, it was more important to identify different types of persons to interview than to find a homogenous group. The selection includes students, external supervisors, and examiners, and thesis projects from three different universities. Based on the available resources, it was decided to cover an adequate set of roles and thesis projects, instead of requiring that all roles were interviewed for all the thesis projects involved. The thesis projects chosen are presented in Section IV-A.

The interviews were conducted by, and evenly divided between, the authors of this paper. Most interviews were conducted in face-to-face meetings between the interviewer and a single interviewee, with a few interviews being conducted by telephone. The interviews were held in Swedish and lasted about an hour each. All interviews were recorded and then transcribed to text.

The interviews were conducted over a period of one month and the interviewers were in contact during this period and discussed the interviews. However, no changes were made to the interview questions during this period.

3) Definition of codes: Based on the contents of the interview transcripts, and the interview questions, a set of codes was defined. The codes represented interesting issues in the text, such as "objective of the student," "resources for student/supervisor," "supervision process at the company," "conflicts," and so on. In total 19 main codes were defined, with some of the main codes being divided into sub-codes. The codes were related to the research questions, although enriched with findings from studying the transcripts.

The text segments of the interview transcripts were marked with the codes, and frequently with multiple codes.

4) Definition of subjects: Subject areas were defined. For all subject areas a set of related codes was derived. The subject areas correspond to all but the first sub-sections of Section IV.

5) Summarizing information about subjects: The findings concerning every subject area were summarized in one short text each. These summaries are presented in Section IV. The analysis of the interview data up to this point mostly resembles what Yin [16] describes as "developing a case description."
The advantage of this approach is that it gives a good understanding of the subject areas. Although no advanced models of relationships are derived, it gives a sufficient understanding to derive requirements for support for different stakeholders.

The citations from the interviews presented in this paper have been translated from Swedish to English.

6) Deriving requirements for support: Based on the findings from the interviews, the different kinds of support that are necessary, based on the interviews, are described. The intention is not to present complete checklists and descriptions, but to describe what type of support is necessary.

\section{Validity}

Based on the design of the study, it is possible to discuss the validity (see e.g., [16]) of the findings.

1) Construct validity: This concerns the extent to which the metrics studied really represent what the researchers have in mind. In this study it can be assumed that the concept that was analyzed (the Master's thesis project) was well known by all interviewed subjects, and that the questions and their answers were rather straightforward, which means that the risk of misconceptions is not very large. All questions were also discussed by all authors, which minimizes misunderstandings. Based on this, these kinds of threats are not seen as very severe.

2) Internal validity: This is concerned with threats to conclusions about cause and effect relationships. Since the major objective of the study is not to derive this kind of conclusions, this is not seen as a severe threat.

3) External validity: This is concerned with generalization of the results from the chosen population and the tasks that have been studied. The major threat to the validity of this study is probably to do with the sampling of involved subjects, which was based on convenience, i.e., students or supervisors who had recently finished their projects and therefore were more likely to take part in the study. One effect of this could be that no "problematic" thesis projects were included. Even if not all thesis projects included were considered "optimal" by all parties, there was no really problematic project involved. It is probably less likely that people involved in failed or heavily delayed projects would have been willing to take part in the type of research that is reported here. However, this probably does not mean that the conclusions are invalid, only that they are potentially incomplete. In future work, it would be possible to interview stakeholders during thesis projects, which might remove some of the bias in sampling that only considering successfully finished projects creates.

All the thesis projects investigated were conducted by Swedish students and with Swedish supervisors. Even though this might be a validity threat, the findings seem general enough that they should also hold for other countries with similar thesis projects.

The sampled projects are all from the area of "software engineering." However, many of the findings are probably generalizable to other areas, as long as cooperation between the university and the industry and other organizations is common. 
TABLE I

THESIS PROJECTS AND INTERVIEWED PERSONS

\begin{tabular}{|l|l|}
\hline Thesis project & Interviewee \\
\hline \hline 1. Retail & $\begin{array}{l}\text { Student 1 } \\
\text { Industrial supervisor 1 }\end{array}$ \\
\hline N/A & Examiner 1 \\
\hline 2. Consultancy & Student 2 \\
\hline 3. Embedded, test & $\begin{array}{l}\text { Student 3 } \\
\text { Industrial supervisor 2 }\end{array}$ \\
\hline 4. Telecom, performance & $\begin{array}{l}\text { Student 4 } \\
\text { Industrial supervisor 3 }\end{array}$ \\
\hline 5. Modeling & Examiner 2 \\
\hline
\end{tabular}

4) Reliability: This is concerned with to what extent the data and the analysis is dependent on the specific researchers. Hypothetically, if another researcher subsequently conducted the same study, the result should be the same. In this study all findings were either derived by the researchers in cooperation, or they were reviewed by the other two researchers, which means that this threat has been addressed.

\section{RESUlts}

\section{A. Characterization of Included Theses, Students, and Orga- nizations Involved}

Most of the interviews concerned a specific thesis project. At one of the participating universities, one individual is the examiner of all Master's theses in software engineering. At the other two universities, any senior faculty member can be the examiner. People from five different thesis projects were interviewed. The thesis projects and the interviewees are summarized in Table I.

Project 1 was conducted by two students at a software company developing retail applications. The goal was to develop a process for market-driven requirements management. One of the students and the industrial supervisor were interviewed. Examiner 1 is from the same university as Project 1, although he had that role a few years before Project 1 . In Project 2, a student was interviewed. The student worked for a consultancy firm and the work was performed at one of that company's customers, a large telephone and Internet service provider. The student's task was to investigate how the customer's organization could be adapted to the use of a specific software development process. Project 3 aimed to improve the way a large company worked with software testing of embedded software systems. The work was conducted at the company by two students. One of the students and the industrial supervisor were interviewed. In Project 4, two students conducted a project on behalf of a large telecommunications company, but with their physical workplace at the university. The purpose of this project was to develop software for performance monitoring of one of the company's products. One faculty member at the university played the role of academic supervisor as well as industrial supervisor, and was paid part-time by the company. One of the students and the academic/industrial supervisor were interviewed. That is, "Industrial supervisor 3" according to Table I, acted both as industrial supervisor and academic supervisor. Project 5 was conducted by one student at a company developing different types of real-time systems.
The goal was to evaluate a tool for modeling software for such system. The examiner was interviewed.

The thesis projects involved development of different types of artifacts. For example, in Project 1 and Project 2, a high level process for an organization was the target for the project, and in Project 3 the project focused on methods and tools in a sub-processes of larger processes. In Project 4 the development concerned a software product.

\section{B. Characterization of the Master's Thesis Project Process}

The same four steps that were the basis for the formulated questions could be confirmed in the interviews, i.e., start-up, planning, execution, conclusion.

1) Origin of thesis projects and formulation of goals: In all cases, the original idea for the project came from the company. Examiner 1 confirms that it is common for projects conducted at companies to be based on ideas from the company. The examiner noted that longer term, the university could build up a closer collaboration with companies and thus co-create initial ideas and topics. However, in practice this is not yet common.

The formulation of the detailed goals for the projects was achieved through a dialogue between the company on the one hand, and the students and the university on the other. One common concern of both students and universities is to ensure that academic goals can be met. In some cases, the company is interested in having some concrete work done, for instance software development. In other cases, the company is more interested in conducting an investigation, while the students are the ones most interested in doing technical work. In many cases, the goals tend to be formulated mostly according to the wishes of the company.

The process of formulating the goals differs somewhat among the projects studied, with respect to how formally the process is conducted. In some cases, the university takes on the main responsibility for formulating a set of minimum requirements to be met by a project to be approved, along with additional desirable goals. This type of process may benefit from the experience of university staff in formulating goals appropriate for thesis projects of a certain stipulated workload. In other cases, the project goals are formulated mostly through negotiation between the company and the students, although the university is always responsible for approving the planned thesis project.

2) Planning and starting up the projects: After the goals of a project have been formulated, the next step is to make a plan for how to achieve these goals. In the projects studied, the students planned the projects rather independently. Since training in project planning is an educational goal of the thesis project, it can be argued that it is appropriate that the students should be responsible for the planning. A common problem, however, is that some activities require participation by the industrial supervisor or other people from the company. A typical example among the projects in this study is that the students plan to spend some time at the beginning of the project to learn about the company's existing systems, processes, or organization, but run into problems because they 
cannot get the required help from people at the company. In Project 4 this was avoided by giving the students a "crash course" in the system, which was planned in advance by the industrial/academic supervisor and appreciated by the student.

3) Conducting and supervising the thesis projects: All the thesis projects included in this study had a stipulated workload of 20 weeks of full-time study for each student. All the interviewed students stated that they spent approximately this amount of time to complete their theses.

Industrial supervisors 1 stated that it was difficult to estimate how much time was spent on supervising the project, but that it was probably less than anticipated at the start of the project. For this particular project, a reference group of other company representatives was set up with the purpose of continuously providing feedback, for example by reviewing draft documents. Due to the general high workload, the members of the reference group were also able to spend less time on the project than initially intended.

4) Reporting the results of the thesis projects: All thesis projects are required to produce a written report, which is the main basis on which the project is evaluated by the examiner. Furthermore, an oral presentation and defense are mandatory. In addition, most of the projects in this study presented their results to the company in additional documents and oral presentations. Examples of documents include user documentation for developed software and more extensive reports with classified information.

Several of the students stated that oral presentations turned out to be much more important than the written documents. Presentations where mostly engineers were present tended to generate much discussion.

\section{Requirements on Thesis Projects According to the Inter- views}

There are a number of requirements for a thesis project, especially from the university. These concern, for example, the novelty for and contribution to the (research) community, and how the methodology is chosen and presented.

Concerning what the interviewees regard as methodology, nothing was said about traditional research methods such as controlled experiments, surveys, case studies, or action research. Instead some interviewees mentioned terms like "proof of concept," "prototyping," and "the choice of an iterative process" as methodology. The most common approach for these projects is a prototyping approach where a solution to a problem is improved iteratively. This is reasonable in this kind of project, but few of the interviewees chose to describe this in general terms. In some cases, "literature search" was mentioned in the presentation of the methodology.

Two interviewees mentioned that a requirement for a Master's thesis project is that it is "near research," or that something new is developed in the project. One of the students also considered this a difficult requirement to achieve in the planning phase of the project. That is, the student thought it was hard to propose and define a project that was investigating a new area, resulting in new knowledge, but at the same time possible to complete in the given time frame with his limited experience.
Two other interviewees regarded experience from typical engineering work as a learning objective of the thesis project.

\section{Objectives and Incentives for Different Stakeholders}

The interviewees agreed that an important objective for the organization is that they can have a question investigated, such as a new idea of how something can be solved technically or how a work process should be designed for a certain task. The interviewees also expressed that the organization can see a thesis project as a suitable way of trying out the new idea in order to see whether it really is a good idea in practice. For example, Industrial supervisor 2 clearly stated that both positive and negative results are useful for the organization:

"Often it is the things that go wrong that is interesting knowledge for us, even more interesting than the things that work as expected"

The type of question that the organization wants to have investigated concerns in many cases issues that are of longterm interest, but not possible to investigate directly as part of the organization's ongoing projects. This is probably due to a natural conflict between short-term and long-term objectives in an organization. It may be that people in the organization see a long-term question as interesting and important, but the shortterm obligations in ongoing projects are of higher priority since they are more directly related to producing results.

Another important objective for the organizations is to be able to recruit personnel from thesis projects. Almost all interviewees, including external supervisors, mentioned this as an important reason for starting a thesis project. For example, Student 3 expressed this as

"[Name of supervisor] wanted us to start working there. They never said that 'we have thesis projects because we want to recruit new personnel', but that was the feeling I got."

This is supported by what the supervisor said in the interview. For the students, one important objective is, of course, to finish their education. They also expressed an interest in getting contacts with potential employers, and to obtain experience that is relevant once they have graduated and apply for positions with an organization.

One supervisor also mentioned that there is much valuable technical knowledge that can be obtained by cooperating with a university. That is, one objective of having Master's thesis projects is to have an ongoing contact with a university.

\section{E. Result of Thesis Projects}

The results of a thesis can differ in how they are useful for the organization that commissioned and supported the project. The investigated thesis projects differed as to whether they were focused directly on the products of the company, on internal processes or on the organization itself. Another variation concerned how much additional effort is needed before the result is actually used by the organization.

Product- or service-related results are more often useful without requiring much additional effort. Examples given by interviewees were improvements or extensions of existing 
tools or products, but also development of new tools or prototypes for new products. A common use of theses projects is also to explore new and often high-risk areas or techniques. As mentioned in Section IV-D, companies often work under strict time pressure and do not have the time to explore alternatives or new ideas. Several interviewees considered such exploration and the insights about new techniques that they give, to be one of the more important results for thesis projects. For example, Industrial supervisor 2 expressed the following:

"We have a high pace in our development so we focus on surviving, we have to test certain areas and press forward, but we do not get the time to explore new ideas that could improve things in the long term. There are few resources for improvement work. The theses we have had often focus on very interesting topics. Almost like research into an area where we have not had any knowledge"

Thesis results that concern the processes of the organization are often directly useful but require additional effort actually to be put into practice. Several results that more indirectly affected the organization were described in the interviews. One example, stated by several interviewees, is that they have seen that a thesis project results in an increased focus on an area or problem and thus helps raise awareness and indirectly makes future changes or decisions easier. Another, related, example is that the result of a thesis can be used to convince upper management that a certain decision is necessary.

Thesis results that are not immediately useful are acted upon in two main ways. Either they lead to new thesis projects, which build upon the first, or they lead to internal staff further refining the results. However, several interviewees mentioned that there is often a lack of continuity. Opportunities may be lost since the organization does not act on the results even though they want and are able to.

The projects differed in how they fit into the normal work of the organizations. Several were carried out within the organizations but not many were within the key business processes.

In conveying the result to the organization, several interviewees mentioned that the presentation of the thesis results at seminars and other meetings is very important. Often this is more important than the thesis report itself. Not many people in commercial companies have the time to read traditional reports so the presentation is crucial. This is especially true for the managers who will take the final decision on how to act on the results of the thesis.

\section{F. Conflicts and Discussions}

Not many conflicts or discussions were mentioned in the interviews. However, one source of conflict concerns the level of technical detail. In Project 3 the student wanted more technical depth than was possible in the chosen project. Neither the company nor the examiner were interested in this much technical detail and finally the project included no implementation (software coding) at all. In this project the student agreed to do only an evaluation without any coding in order to be able to complete his thesis project. In another project the students felt that the company wanted more technical depth than the examiner. The company wanted more concrete results requiring technical implementation while the examiner was more concerned about theory and methodology than the other stakeholders. This was not confirmed in the interview of the supervisor so it may only be the student's interpretation.

Another important discussion concerns what to include in the report and how to present the organization and the problems investigated. In Project 3, for example, this discussion concerned what information could be included due to confidentiality issues. In Project 1, there was a discussion since different individuals did not agree with a problem definition for the organization.

\section{G. Identified Improvements for the Thesis Process}

The respondents differ in how clearly they think the quality of a thesis can be judged. However, they agree that different stakeholders have different quality criteria. The companies focus on the concrete and how the results can be applied in their products or processes. For academia it is more important to compare techniques, build new theories or find correlations and causations between different factors. There is definitely a tension here; several respondents mentioned that in order to fulfill the academic requirements there is less time actually to implement or test the ideas that are most relevant for the companies. To handle this it is very important that all stakeholders have an understanding of each others' views and criteria.

Many respondents mention that the language in the report is very important for the perceived quality. A good and easily readable English can make even lower quality results look good. Language is also important in the oral presentation. Industrial supervisor 2 wants more focus to be put on the oral presentation:

"Often they have done the written thesis and do a few slides. But really, they should spend several days on developing the oral presentation."

A common problem in thesis projects is that supervisors do not have enough time to support the students. All industrial respondents said that they would have wanted to put more time into supporting the students. Industrial supervisor 1 believes that the supervisor should talk to the students at least two or three times per week. However, several of the students seem to have a realistic view of this and do not expect the supervisors to have extensive time for them. They especially would like to see more support early in the projects when they often are more unclear about how to proceed.

A thesis can also be indirectly of high value if it indicates problems with the products the company develops. This can happen as a side effect, since the thesis projects use the products, tools or processes differently than foreseen by the staff who developed and are used to them. This indirect knowledge is often left out of the thesis report itself. A log can be crucial in collecting this kind of knowledge.

Some of the interviewed students requested more support and information from the university about how to succeed with the thesis project. 


\section{Discussion}

One finding from the interviews is that it is important to strengthen the knowledge of methodological questions for all involved roles. All roles should be able to express the methodology in adequate terms in order to be able to discuss and understand why a thesis project should be conducted in a certain way.

Another issue concerns the requirements for examination of thesis projects. This must be reasonably clear to all involved roles, also at early stages of projects. If this is not the case there is a risk that unnecessary or even wrong questions are addressed in the project. It is, of course, natural that different parties have different objectives, but it is positive if this is made clear to all roles. Different ways in which examination requirements and quality criteria can be made more explicit has been studied in [19].

It was also found that the presentation format is important. Both the quality of the report and the quality of the oral presentation is important, both as a basis for examination and to bring value to the organization that has invested effort in the thesis project.

An often-mentioned problem in the interviews is the limited availability of industrial supervisors and other people from the companies, especially in the early phases of a thesis project. Two of the projects studied seem to stand out from the rest in the sense that this was not seen as a problem. In Project 4 this was largely due to the fact that the company had funded one person at the university specifically to work with supervision of thesis projects, which is not a practice one can expect companies to adopt in general. In Project 1, the company took their first thesis project very seriously and had both a supervisor with whom the students had daily contacts, as well as a reference group with meetings throughout the project. It seems crucial that much support should be given from the university in the early phases, both in written form but also in discussions with the examiner or academic supervisor. With this in place, differences in how the companies handle the startup phase might be partly alleviated. However, support material for the industrial supervisors should also point out how important the startup phase is to the success of the project, and outline the kind of information that is needed.

For the thesis projects in this study, measures such as those discussed above would have helped the students to work more efficiently and thereby increase the companies' benefits from the projects. Attempting to extrapolate the findings to projects with weaker students, the value of such measures is probably no less.

Concerning the support that is needed it was clear in the interviews that there were some problems that are general for all thesis projects. These concerned for example what the criteria for approving a thesis project are, and how a typical project process for this kind of project should be defined. During the interviews, it was also clear that there is a clear difference between projects that are carried out at a university and projects that are carried out in industry. It was also clear that all involved roles, except the students, had very limited effort available to spend on the project. This means that it is

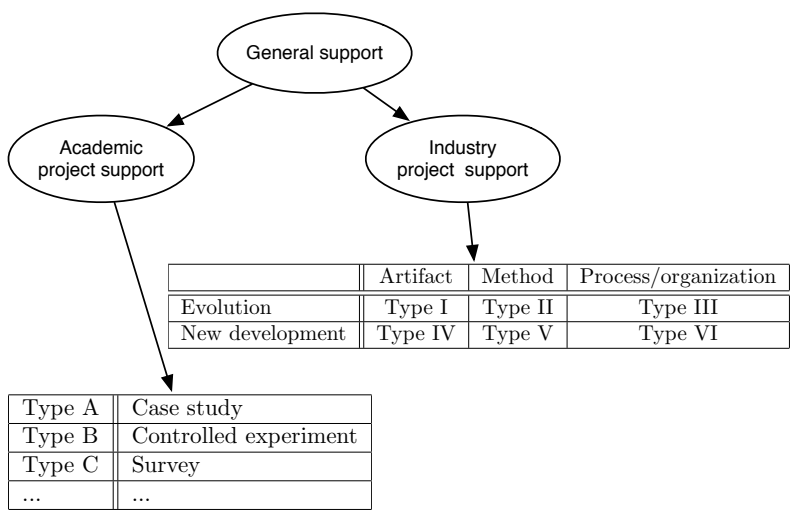

Fig. 2. General overview of the support model

necessary to adapt the support to the different involved roles. It was also possible to see differences between different kinds of thesis project, such as projects working with new development and projects working with evolution of an existing baseline.

\section{CONCLUSIONS AND FURTHER WORK}

Based on nine interviews of different roles in software engineering Master's thesis projects, it can be concluded that different roles have different objectives with thesis projects. For example, typical objectives for students are to get in contact with industry and to conclude their studies, and typical objectives for industry contacts are to have a question investigated and get in contact with potential future employees. Industrial organizations have a clear objective to investigate new concepts, methods, and ideas, for which it is hard to find resources in their normal ongoing projects. This means that the expectations for the projects can differ for different roles, and that the perceived challenges can differ. There are requirements for thesis projects from universities, but these requirements are not always clearly communicated between the university, the external organizations, and the students.

A model to support different roles and different types of projects could be formulated. It is beyond the scope of this article to present detailed support information, but it can be concluded that different types of support are needed in different kinds of thesis projects and for different stakeholders. Fig. 2 presents one suggestion of a support-model based on the interviews. The support model has two main dimensions: project type and stakeholder role. For the project type there are three distinct levels: general Master's thesis level, base level, and project level.

The general Master's thesis level should have general support information for Master's thesis projects that is specific to the subject area (e.g., software engineering) and the university. This could include a general description of the steps involved in a thesis, deadlines, roles and how the quality will be judged.

The project level then differs based on whether it is an academic project or an industrial project. Academic projects have not been studied carefully in this research. Here it is assumed that support for different research methods is suitable, although this could be studied more carefully in further work. The project model for industry projects can be further 
broken down into more detailed categories that are specific to software engineering theses. Type I, II, and III projects concern evolution of either an artifact, a method or a complete process. In these kinds of projects it is, for example, necessary to give support on how to identify the owner of the object of study and ensure support for the project. It is also important to study existing objects and their limitations. Type IV, V, and VI projects concern development of new objects. In these projects it is more important to identify contact persons in order to investigate the need for and requirements on the new object, and to conduct a general investigation of background material. The other dimension on the table concerns the type of object that is the focus for the project. The interviews showed that the type of object is important in determining the type of activities during the project, and thus needs different types of support. These six classes are based on the interviews and knowledge of the area, but they should be subject to further research, and refinements and adaptations may be necessary. The support may then be refined based on role. In particular industrial supervisors, with their limited time, will need tailored support.

Recommended actions for universities wanting to support this kind of thesis project include first of all making a comparison of existing support at the university against the support model presented in this section. Such a comparison should make it possible to identify important types of thesis projects for which more detailed support in forms of checklists, tutorials, web-pages, and so on, that can be developed. This kind of support can then be evaluated through practical use in conducted thesis projects.

\section{ACKNOWLEDGMENT}

The authors would like to thank all interview subjects, and they would also like to express their gratitude to Gordana Dodig-Crnkovic for valuable comments on an earlier version.

\section{REFERENCES}

[1] Joint Task Force on Computing Curricula, "Software Engineering 2004: Curriculum guidelines for undergraduate degree programs in software engineering," IEEE and ACM, Tech. Rep., Aug. 2004. [Online]. Available: $\mathrm{http} / / /$ sites.computer.org/ccse/

[2] Stevens Institute of Technology, "Graduate Software Engineering Reference Curriculum (GSwERC) version 0.5," Stevens Institute of Technology, Tech. Rep., October 2008. [Online]. Available: http://www.gswerc.org

[3] C. Wohlin and B. Regnell, "Strategies for industrial relevance in software engineering education," J. Syst. and Software, vol. 49, no. 2-3, pp. 125 34, 1999.

[4] P. A. Laplante, "An agile, graduate, software studio course," IEEE Trans. Edu., pp. 417-419, November 2006.

[5] C. Anderson, K. Day, and P. McLaughlin, "Mastering the dissertation: lecturers' representations of the purposes and processes of Master's level dissertation supervision," Studies in Higher Education, vol. 31, no. 2, pp. 149-168, April 2006.

[6] M. Hammick and S. Acker, "Undergraduate research supervision: A gender analysis," Studies in Higher Education, vol. 23, no. 3, pp. 335347, October 1998.

[7] M. Todd, P. Bannister, and S. Clegg, "Independent inquiry and the undergraduate dissertation: perceptions and experiences of final-year social science students," Assessment \& Evaluation in Higher Education, vol. 29, no. 3, pp. 335-355, June 2004.

[8] O. Ylijoki, "Master's thesis writing from a narrative approach," Studies in Higher Education, vol. 26, no. 1, pp. 21-34, March 2001.

[9] T. Gröhn, A. Kauppi, M. Ranta, J. Jansson, and S. Paananen, Developing Teaching and Learning in Higher Education. Helsinki University Press, 1993.
[10] European Ministers of Education, "The European Higher Education Area - The Bologna Declaration of 19 June 1999," European Commission, Bologna, Italy, Tech. Rep., June 1999.

[11] Eurydice, "Focus on the Structure of Higher Education in Europe 2006/07 - National Trends in the Bologna Process," Eurydice European Unit, Tech. Rep., 2007.

[12] Bologna Secretariat, personal communication, January 2009.

[13] Tuning General Brochure, "Introduction to Tuning," European Union Directorate of Education and Culture, Brussels, Tech. Rep., 2006.

[14] S. Reichert and C. Tauch, "Trends IV: European universities implementing bologna," European University Association, Tech. Rep., 2005.

[15] R. Jeltsch and K. Nipp, "Adapting the CSE program at ETH Zurich to the Bologna Process," in Computational Science (ICCS), Krakow, Poland, 6-9 June 2004, pp. 1196-1201.

[16] R. K. Yin, Case Study Research, Design and Methods, 3rd ed. Sage Publications, 2003.

[17] C. Robson, Real World Research, 2nd ed. Blackwell, 2002.

[18] S. E. Hove and B. Anda, "Experience from conducting semi-structured interviews in empirical software engineering research," in Proc. IEEE International Software Metrics Symposium (METRICS 2005), 2005.

[19] R. Feldt, M. Höst, and F. Lüders, "Generic skills in software engineering Master thesis projects: Towards rubric-based evaluation," in Proceedings of the Conference on Software Engineering Education \& Training (CSEE\&T 2009). IEEE Computer Society, February 2009, to appear.

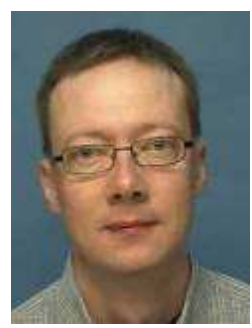

Martin Höst (M'94) is an Associate Professor in Software Engineering in the Software Engineering Research Group at the Department of Computer Science, Lund University, Sweden. He received an M.Sc. degree from Lund University in 1992 and a Ph.D. degree in Software Engineering from the same university in 1999. His main research interests include software process improvement, empirical software engineering, software performance engineering, and computer simulation of software development processes. The research is conducted through empirical methods such as controlled experiments, surveys and case studies. Dr. Höst has published more than 40 papers in international journals, conference proceedings and workshop proceedings. Dr. Höst has supervised 27 Master's thesis projects and is co-author of a Swedish text book on conducting Master's thesis projects

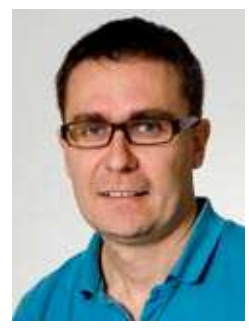

Robert Feldt (M'98) is an Assistant Professor in Software Engineering in the Software Engineering Research Laboratory at the BESQ research center, Blekinge Institute of Technology, Sweden. He received an M.Sc. degree from Chalmers University of Technology in 1997 and a Ph.D. degree from the same university in 2002. His main research interests include software testing and verification and validation, automated software engineering, psychology of programming, user experience and human-centered software engineering. The research is conducted mainly through empirical methods such as controlled experiments, surveys and case studies, but also through technical and theory development. Dr. Feldt has published more than 20 papers in international journals, conference proceedings and workshop proceedings. He has supervised 18 Master's thesis and examined an additional 35 Master's thesis at three different Swedish universities. 


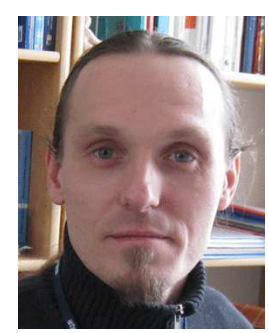

Frank Lüders (M'02) is an Assistant Professor in Software Engineering at Mälardalen University, Sweden. He received a M.Sc. degree from the Technical University of Denmark in 1997 and a Ph.D degree from Mälardalen University in 2006. His main research interests include software architecture, component-based and model-driven software development, and embedded real-time systems. The research is mainly conducted through empirical methods. Dr. Lüders has published more than 10 papers in internationally refereed books and conference proceedings. He has supervised 14 Master's thesis projects. 